Association for Information Systems

AIS Electronic Library (AISeL)

\title{
Organizing for Digital Innovation and Transformation: Bridging Between Organizational Resilience and Innovation Management
}

Daniel Heinz

Karlsruher Institut für Technologie

Fabian Hunke

Karlsruher Institut für Technologie

Gregor Felix Breitschopf

The London School of Economics and Political Science (LSE)

Follow this and additional works at: https://aisel.aisnet.org/wi2021

Heinz, Daniel; Hunke, Fabian; and Breitschopf, Gregor Felix, "Organizing for Digital Innovation and Transformation: Bridging Between Organizational Resilience and Innovation Management" (2021). Wirtschaftsinformatik 2021 Proceedings. 15.

https://aisel.aisnet.org/wi2021/XStudent/Track03/15

This material is brought to you by the Wirtschaftsinformatik at AIS Electronic Library (AISeL). It has been accepted for inclusion in Wirtschaftsinformatik 2021 Proceedings by an authorized administrator of AIS Electronic Library (AISeL). For more information, please contact elibrary@aisnet.org. 


\title{
Organizing for Digital Innovation and Transformation: Bridging Between Organizational Resilience and Innovation Management
}

\author{
Daniel Heinz ${ }^{1}$, Fabian Hunke ${ }^{1}$, Gregor Felix Breitschopf ${ }^{2}$ \\ ${ }^{1}$ Karlsruhe Institute of Technology (KIT), Institute of Information Systems and Marketing, \\ Karlsruhe, Germany \\ daniel.heinzestudent.kit.edu, fabian.hunke@kit.edu \\ 2 The London School of Economics and Political Science (LSE), Department of Accounting, \\ London, United Kingdom \\ g.breitschopf@lse.ac.uk
}

\begin{abstract}
Increased digitalization offers today's organizations novel opportunities to enhance value propositions for customers, but also poses significant challenges for traditional businesses. To navigate through the difficult process of digital transformation in this turbulent environment, organizations need to integrate successful innovation management practices and build organizational resilience.

In this paper, we propose a conceptual framework that bridges between these two constructs: We describe innovation management as the continuous activity of anticipating and responding to ongoing trends in an organization's environment through innovation, whereas we understand organizational resilience as the capability to adapt or transform an organization's business. By analyzing two illustrative cases, we find indications that a successful digital transformation is not possible without one or the other. Furthermore, we contribute key factors for building organizational resilience and showcase two examples of how to leverage organizational resilience by transforming business models through digital innovation and, thus, avoiding the innovator's dilemma.
\end{abstract}

Keywords: Organizational Resilience, Digital Transformation, Innovation Management, Digital Innovation, Digitalization.

\section{Introduction}

The unprecedented success of modern tech-companies, e.g., Amazon, Netflix, or Uber, illustrates the impact of the ongoing wave of digitalization [1]. Novel business potentials challenge traditional companies to reinvent themselves by transforming their business models and internal processes to remain competitive in the digital age $[2,3]$. The ability to detect relevant technological advances and to anticipate their business applicability has become a strategic necessity across industries [2, 4]. The continuous process of digital transformation requires companies to successfully integrate digital 
innovation management practices into their workflow [5]. The need for digital innovation challenges extant innovation management theory $[6,7]$ and requires research priority to lead the transition process from innovation management towards digital innovation management [5].

To contribute, we suggest organizational resilience as a mean to exploit digital innovation opportunities and organize for these temporal windows of opportunities to successfully navigate through the challenging digital age [5]. Organizational resilience describes an organization's ability to remain successful by undergoing adaptive or transformative processes when facing challenges and adversity. Furthermore, being resilient not only implies reacting to external forces, but rather creating the conditions to anticipate unknown but high-risking threats and, thus, allows them to stay in control and act flexibly and adaptively. In contrast, we see (digital) innovation management as a set of ongoing practices and processes to anticipate and respond to ongoing trends in an organization's environment through (digital) innovation.

This study addresses this potential linkage by asking the following research question: "How are the research streams of organizational resilience and digital innovation management interrelated, which related insights from organizational theory enhance knowledge in IS research about digital innovation and transformation, and what are fruitful areas of future research to strengthen the linkage between both concepts?".

As a first step to address this broad research question, we analyze two illustrative success stories of digital innovation and transformation [8] - 1) Apple's innovation of the iPod and iPhone enabled through digital technology, and 2) Netflix's transformative and adaptive capabilities by reinventing itself as a leading streaming provider for video content. We retrieve success factors for building organizational resilience and, thereby, identify organizational resilience as a critical enabler for companies to strive and grow their business by digitally transforming existing business models. Subsequently, we put our findings in the context of digital transformation by outlining how state-of-the-art innovation management research should adapt ideas of organizational resilience theory as part of a transition towards digital innovation management. We contribute by bridging between the concepts of organizational resilience originated in organizational theory and digital transformation and (digital) innovation management in IS research and provide possibilities for future research endeavors. Practitioners might also benefit as we showcase two examples of how to leverage organizational resilience by transforming business models through digital innovation [9] and, thus, avoiding the innovator's dilemma [10].

In the following chapter, we compile foundational and related work on organizational resilience as well as digital innovation management and digital transformation. In Chapter 3, we define organizational resilience with a conceptual framework and derive nine potential success factors from related literature. Additionally, we present a systematic procedure for the conducted cross-case study. We examine the two cases of Apple and Netflix as success stories of a resilient adaptation to technological change in Chapter 4 and discuss our findings across both cases. In Chapter 5, we put our results into the context of digital transformation and innovation management, summarize our findings, address the limitations of our study, and point out possibilities for future work. 


\section{Foundations and Related Work}

\subsection{Organizational Resilience Research}

The term "resilience" was shaped by two scientific currents in the 1970s and early 1980s: The ecologist C. S. Holling [11] introduced the concept of resilience to describe the survivability of an ecological system; the psychologist E. Werner [12] examined factors of resilience that helped children and adolescents to successfully deal with biological and psychosocial risk factors. With their pioneering work, the authors established two competing approaches to study resilience, namely systemic resilience and personal resilience.

In economic sciences, the work of Staw et al. [13] and Meyer [14] on organizational responses to external threats was pioneering. In the 1980 s, measures to increase internal reliability and security moved into scientific focus, with resilience being examined as part of the strategy of high-reliability-organizations [15]. Linnenluecke [9] divides the subject of contemporary organizational resilience research into three main topics: The management of employee strengths [16-18], resilient supply chain design [19, 20], and the adaptability of business models. In the following, we mainly focus on literature related to the latter topic since the adaptability of business models is the most relevant in the context of our study. This type of resilience, often coined as organizational resilience [21, 22], combines aspects of both systemic and personal resilience research.

Sutcliffe and Vogus [21] examine organizational resilience as a means of creating conditions for successfully using internal and external resources to deal with threats. They investigate possible conditions at several levels of the organization (individual, team, organizational). In Chapter 3, factors of organizational resilience are presented in more detail. Hamel and Välikangas [23] emphasize the innovative capacity of companies as a decisive criterion for measuring organizational resilience. They see it as a serious challenge for established companies to create a suitable corporate culture and hierarchical structures to anticipate future disruptions and remain adaptable by developing novel business models or products.

Endres et al. [24], on the other hand, tie in with past research (e.g. [15]) by describing a significantly increased vulnerability of modern companies in times of digitalization and related paradigms such as the Internet of Things and Industry 4.0. The authors, therefore, recommend establishing resilience management practices as an evolution of risk management on best-practice learnings from high-reliability-organizations. Particularly, this includes the establishment of a positive error culture to identify weaknesses and, thus, initiate learning processes, and a shift of operational decisionpower away from non-specialized management towards the employees with the most specific expertise.

Palzkill and Schneidewind [25] transfer existing systemic resilience research to management theory by introducing the concept of Business Model Resilience. They use dimensions of resilience, which were previously introduced by Walker et al. [26] to describe socio-ecological systems and, hence, obtain appropriate management strategies. In doing so, they differ between the relevance of risks due to vulnerability (precariousness and latitude) and the (non-)transformability of an organization 
(resistance and panarchy). Based on this, the authors point out that the resilience of a system is always directly related to the resilience of its super- and sub-systems $[25,26]$. Thus, organizational change requires not only the company's resilience capabilities as a closed system but also the adaptability of its employees or departments (sub-system) as well as its environment, e.g. a local community or business partners (super-system). As an illustrative example, the authors discuss the finite nature of fossil resources as a threat to the automotive industry. In this context, the business model of offering shared electric vehicles might be an alternative strategy to create value while mostly maintaining its initial value proposition. In the establishment of this adaptational or transformational process, the business model resilience of the organization, and especially the internal and external transformability (resistance and panarchy), play a major role in the successful establishment of this business model innovation [25].

\subsection{Digital Innovation Management and Digital Transformation}

The wave of digitalization has an impact on many different levels and, thus, exerts holistic pressure on companies and their business models [1]. Changing conditions that confront companies include shifting customer expectations and work processes, new sales channels and markets, social media, real-time information and availability, and a range of new possibilities through the analysis of existing data [2, 27]. Throughout our study, we refer to different related concepts in this context, namely digitalization, digital transformation, digital innovation, and digital innovation management. In Table 1, we provide a brief definition of our understanding of the respective concepts and link to related work in IS research.

Table 1. Key concepts in the context of digital innovation management.

\begin{tabular}{|c|c|}
\hline Concept & Summary and Related Work \\
\hline Digitalization & $\begin{array}{l}\text { The sociotechnical phenomena and processes of adopting and } \\
\text { using digital technologies in broader individual, } \\
\text { organizational, and societal contexts }[1,28] \text {. }\end{array}$ \\
\hline $\begin{array}{l}\text { Digital } \\
\text { Transformation }\end{array}$ & $\begin{array}{l}\text { The process that aims to improve an entity by triggering } \\
\text { significant changes to its properties through combinations of } \\
\text { information, computing, communication, and connectivity } \\
\text { technologies }[29,30]\end{array}$ \\
\hline $\begin{array}{l}\text { Digital } \\
\text { Innovation }\end{array}$ & $\begin{array}{l}\text { The creation of (and consequent change in) market offerings, } \\
\text { business processes, or models that result from the use of } \\
\text { digital technology [5,7], which can include activities of } \\
\text { initiating, developing, implementing, and exploiting [31]. }\end{array}$ \\
\hline $\begin{array}{l}\text { Digital Innovation } \\
\text { Management }\end{array}$ & $\begin{array}{l}\text { The practices, processes, and principles that ensure the } \\
\text { effective orchestration of digital innovation [5]. }\end{array}$ \\
\hline
\end{tabular}

Digital technological advancement is an essential foundation of digital business models and forces companies to react to the emerging digital environment [3, 4, 32]. Studies such as the Cisco Visual Networking Index [33], according to which the number of 
Internet-enabled mobile devices will exceed the world population by a factor of 1.5 by 2022 , illustrate the rapid progress of digital change. This upheaval can be both an opportunity and a risk for companies. On the one hand, new potential sources of revenue arise for companies due to changes within their business models, such as the introduction of new sales channels or access to new markets [34-36]. Further potential lies in the collection and analysis of data, which can be used to either make internal value chains more efficient, wrap new functions around existing value propositions, or even innovate completely novel business models [37-39]. Besides that, data and analytics can increase the probability of success of marketing measures through targeted customer targeting [40, 41].

At the same time, however, this change also involves a major risk for companies. If a competitor earlier identifies and exploits a window of opportunity for digital innovation, the disruptive characteristics of digital technologies might severely threaten the market position of traditional players [42, 43]. Hereby, established companies often face the innovator's dilemma [10] of having to choose between maintaining still successful business models and uncertain innovations at the expense of current profits. This dilemma might lead companies to (fatal) decisions against innovation for fear of cannibalizing their own business and risking their position as a market leader. Companies that meet the challenges of the digital world with an open mind will therefore benefit - companies that insist on existing structures will lose out [23].

Even though digitalization nowadays affects any industry, the degree of digitalization is not equally advanced across all industries. This difference can be illustrated, for example, by the digitalization index for German SMEs [44], indicating that digitalization is already more advanced in some industries, while other industries could face even more disruptive upheavals. This is the starting point of this work, using the entertainment industry as an example to show how building organizational resilience might enable a company to successfully manage the complex requirements of digitalization. The insights gained from this analysis can serve as a recommendation for future actions so that, especially in less digitized industries, companies can successfully master the transition to the digital age thanks to preventive measures.

\section{$3 \quad$ Research Methodology}

\subsection{Conceptualizing Organizational Resilience}

In this subsection, we present a framework that depicts how organizational resilience impacts the long-term success of a firm. This framework specifies our understanding of organizational resilience and serves as a foundation for our cross-case study. Afterward, we derive potential success factors for building organizational resilience from existing literature. Ultimately, these foundational steps allow us to systematically examine how firms can strive through digital innovation and transformation.

As a systematic literature review of Linnenluecke [9] shows, related literature about resilience in the organizational context does not apply the phenomenon of resilience as a clear distinct concept. For example, resilience is used as a target variable, as a set of 
measures to respond to internal disruptions, or as a positive outcome of recovery efforts after a disaster. In this paper, we refer to organizational resilience as a set of moderating positive systemic and personal factors that are present in an organization already before an immediate threat becomes visible, and which enable an organization facing threats or other adversarial circumstances to successfully deal with them.

Similar to biological or socio-ecological systems in other application fields, organizations cannot strive in adverse conditions only by having resilient characteristics [45]. A system or organization must use its resilient capabilities to trigger transformative or adaptive processes to drive change within the organization itself, for its employees and its stakeholders. While for only temporarily threatening events such as accidents or supply chain difficulties, the return to the initial state might be desirable in the long run, the context of digital innovation requires a permanent transformation of the organization to remain successful [46]. In Figure 1, we propose a conceptual framework depicting how organizational resilience consisting of systemic and personal factors has a positive effect on an organization's long-term business success by triggering transformative or adaptive processes when facing adversarial circumstances.

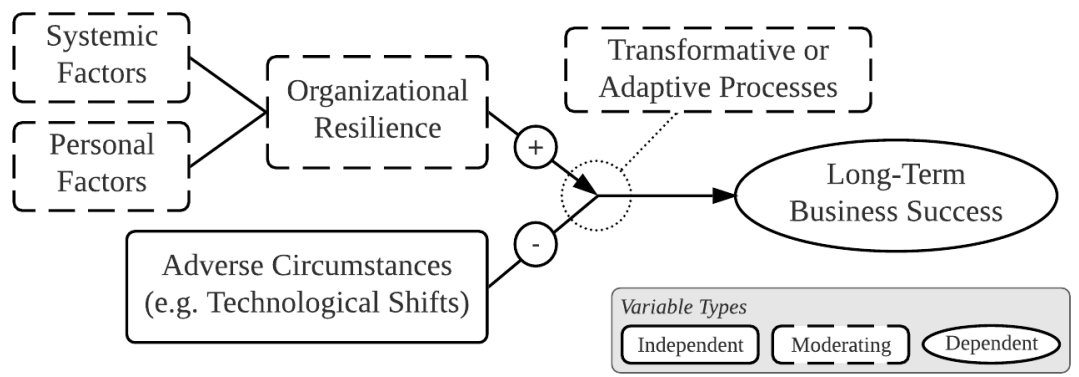

Figure 1. Conceptual framework on the moderating effect of organizational resilience [22].

Several studies grasp the concept of organizational resilience by describing different factors of it. These factors can be classified by the associated level of hierarchy (individual, team, organization, ecosystem), by the respective nature (personal or systemic), or other unifying attributes. For example, a widely recognized work [9] on resilience in organizations of Sutcliffe and Vogus [21] examines factors of organizational resilience at three levels of hierarchy and further divides these factors into two categories: 1) resources that enable the development and maintenance of competencies, and 2) motivation systems and processes that promote effectiveness and growth. Accompanied by a call for more sustainable leadership, Avery and Bergsteiner [47] analyze 23 leadership style elements and identify 3 key performance drivers to build resilience and, thus, enable a long-term successful business performance: strategic and systematic innovation, employee retention, and quality.

In addition to existing scientific literature, we looked into the standard ISO 22316, published in 2017 [48], which describes 9 different factors as principles and attributes of organizational resilience. We found that there is a broad agreement between the wide range of proposed factors of resilience attributes in related literature [15, 21, 22, 25, 47] and the ISO standard. Moreover, recent studies begin to adopt the ISO standard's 
factors as a basis for qualitative empirical studies on organizational resilience (e.g. [49]). Hence, we decided to take the distinct set of nine factors as a starting point for our research and triangulated them by gradually adjusting them following the discussed literature and categorizing them into five systemic (S1-S5), and four personal (P1-P4) factors of organizational resilience. The final set of factors of organizational resilience, which guided our case study analysis, are represented in Table 2.

Table 2. Systemic (S1-S5) and personal (P1-P4) factors of organizational resilience [48].

\begin{tabular}{|c|c|}
\hline ID & Organizational Resilience Factor \\
\hline S1 & Mutual learning by sharing information and knowledge \\
\hline S2 & $\begin{array}{l}\text { Availability of resources to enable rapid adaptation to changing } \\
\text { circumstances }\end{array}$ \\
\hline S3 & Development and coordination of business units geared to strategic goals \\
\hline S4 & $\begin{array}{l}\text { Support of a continuous improvement process to constantly evaluate results } \\
\text { and identify opportunities }\end{array}$ \\
\hline S5 & Ability to anticipate change and manage necessary adjustments \\
\hline $\mathrm{P} 1$ & Shared vision, goals, and values; clarity about the purpose of the organization \\
\hline $\mathrm{P} 2$ & Understanding and influencing the internal and external context \\
\hline P3 & $\begin{array}{l}\text { Effective and encouraging leadership by leaders, e.g. to accept uncertainty } \\
\text { and failure }\end{array}$ \\
\hline P4 & $\begin{array}{l}\text { Positive culture towards values, attitudes, and behaviors that promote } \\
\text { resilience }\end{array}$ \\
\hline
\end{tabular}

\subsection{Case Study Approach}

In this paper, we use a case study-based approach to link the concept of organizational resilience to present research questions in the field of IS, especially in the context of digital innovation management and digital transformation. In doing so, our procedure corresponds to the guidelines developed by Glaser and Strauss [50] and Eisenhardt [8].

Conducting a case study is a common approach in organizational resilience research $[9,22]$, since the organizational effects of resilience can hardly be simulated or reconstructed, and collecting representative data is difficult due to accessibility, timeliness, and confidentiality. As Eisenhardt [8] explains, case studies are particularly suitable in novel research areas such as organizational resilience research. Since real events serve as the basis for theory formation, the author believes that the insights gained from the cases are often universally valid and transferable to other applications.

1) Selection of cases. To select highly-promising cases, Eisenhardt [8] recommends a theoretical sampling approach. In doing so, extreme situations or polar opposable cases are selected that reflect or extend the examined theory by showing a high variation concerning the examined concept. However, regarding concepts not examined in the study, the cases should be mostly similar to keep the influence of confounding factors low. Therefore, we focused on the entertainment industry, which was affected by disruptive technological change early-on throughout digitalization. Throughout the 
selection of cases, we looked out for scientific studies that already linked the concept of organizational resilience with the success of particular companies through digital innovation (cf. [51, 52]) and focused on well-known cases in IS research. With the cases of Apple and Netflix, we selected historical digital upheavals (MP3, DVD, broadband internet access) in the entertainment industry and compared the success factors of both firms with the decline of their competitors Sony Walkman and Blockbuster Video.

2) Data collection and evaluation. It is difficult to collect internal data on resilience in companies (e.g. through questionnaires) due to the high strategic importance and confidentiality of such data. Therefore, we examined the selected cases using existing scientific literature, complemented by journalistic articles and public reports of the firms. The scientific literature was collected through keyword searches in the databases Scopus and Google Scholar as well as forward and backward searches of the included papers [53]. To decide on the relevance of articles, we looked out for technological triggers and factors for success or failure associated with a firm's organizational resilience. Regarding non-academic material, we discussed the quality and added value of the resources among the authors and only included high-quality articles, which added valuable insights to the scientific literature. The final set of the included material is listed in Table 3. By applying the principle of dual control among the authors throughout the data collection and evaluation phase, we obtained complementary insights and ensured the reliability of our results [8].

Table 3. Scientific and non-scientific material included in the case study.

\begin{tabular}{ccc}
\hline Case & Scientific Literature & Additional Material \\
\hline Apple & {$[43,51,54-56]$} & {$[57,58]$} \\
Netflix & {$[52,59-63]$} & {$[64-68]$} \\
\hline
\end{tabular}

3) Within-case analysis and cross-case pattern search. We analyzed both cases in the authors' team by comparing the successful firm with its unsuccessful competitor regarding our proposed framework on organizational resilience. Subsequently, we looked for cross-case patterns, i.e. effective resilience attributes, to distinguish generalizable factors from case-specific characteristics to contribute to the knowledge of organizational resilience in the context of digital innovation management [9].

4) Formation of hypotheses and transferability of the results. Based on the crosscase and case-specific patterns identified throughout our case study, we discussed the relevance and benefits of bridging between existing research on organizational resilience and digital innovation management and digital transformation. By linking these different research strings, we encourage future theory-building to better understand the specifics of digital innovation management [5].

5) Enfolding literature and outlook. In the final step, we tied together our findings with extant literature by analyzing related IS literature for similar findings as well as research in conflict with our results [8]. To deepen the understanding of the linkage between organizational resilience theory and IS concepts, we developed questions for subsequent research endeavors. 


\section{Case Study Results}

In this chapter, we present the results of our cross-case study. For each case, we briefly summarize its outline in a case vignette by describing the initial market situation, relevant technological shifts, and how the market developed throughout the case. Afterward, we focus on the firms' organizational resilience and discuss how it enabled successful digital innovation through adaptational and transformational processes.

\subsection{Organizational Resilience Paved the Way for Apple iPod's Success}

Table 4. Case vignette of Apple iPod's success story.

Case Vignette: Organizational Resilience Paved the Way for Apple iPod's Success

Initial Situation: Sony introduced its Walkman in 1979, which set new standards for portable music devices and revolutionized the music market [57]. Throughout the 1980s, Sony's Walkman became a status symbol and emblem of youth culture [54]. Apple, however, was struggling to compete in its core business of personal computing after Steve Jobs was driven from the company in 1985. Ultimately, in 1997, Steve Jobs returned to Apple and continued leading the company as CEO.

Technological Shift: The progressive spread of PCs, the breakthrough of the Internet, and the invention of digital music file compression (MP3) in the early-mid 1990s made the use of digital storage media conceivable for portable music players [55].

Market Development: While the first respectably successful portable MP3 players appeared in 1998, the most successful one came to market in 2001 with the Apple iPod. The iPod was the first device to fully meet the expectations of customers: A large increase in storage capacity ( $>80 \mathrm{~h}$ playtime) allowed the iPod to unfold the most valuable advantage over physical media and to provide its user a previously unknown level of convenience, accompanied by a simple and plain design and a couple of novel other features [55].

With the introduction of iTunes and the integrated iTunes store in 2003, Apple enhanced its value proposition by offering its customers a service to digitally manage and purchase their favorite music. This marked the final breakthrough of the iPod and digital music services in general [58] and resulted in a dominant market share of up to $48 \%$ for the Apple iPod among MP3 players, accompanied by a rapid decline for portable CD players such as the Sony Walkman [55].

Despite its huge success, Apple remained one of the top innovative companies with products such as the iPod Shuffle and iPod touch. Finally, in 2007, Apple introduced the iPhone - an innovation that, again, changed the whole industry by leveraging mobile data connectivity but also cannibalized most of Apple's iPod sales. With the introduction of the App Store in 2008, the iPad in 2010, and the Apple Watch in 2014, Apple continued to increase its portfolio by innovative marketleading products and services. 
The continuous reinvention of a company through pioneering innovations is considered as a distinguishing feature of resilient companies; especially in today's fast-moving digital world, where business models' life cycles rapidly decline [23]. A closer look at the success story of the Apple iPod, which is described in Table 4, indicates that Apple's business success cannot be explained solely with a one-time successful product innovation. Instead, its ongoing innovation capability indicates that Apple's organizational resilience was a critical success factor throughout the past 20 years [51]. Without this capability, Apple probably would not have been able to identify three highly profitable windows of opportunities (iPod, iPhone, and iPad) in one decade and to provide the necessary resources to make its production a core part of their business. Moreover, with the iTunes Store and the App Store, Apple innovated a new type of digital marketplace and created a whole ecosystem around their physical products [43].

In their study on resilience, Teixeira and Werther [51] classify Apple as an anticipatory company and, thus, distinguish it from reactive and proactive companies. This means that Apple has internal resources and processes (S2) at its disposal to continuously develop industry-changing innovations based on the anticipation of changing conditions (S5). The authors differentiate between Apple's future-oriented opportunity-seeking orientation (S4) and Sony's problem-solving orientation at the time of the introduction of the iPod. According to Teixeira and Werther [51], further enablers were the interaction of leadership and followers (P3), an open corporate culture (P4), strategic planning (S3), and innovation as the "way of life" (P1).

In the case of Apple, two particular aspects should be mentioned: First, the leadership approach and corporate culture that Steve Jobs re-established after returning to Apple as CEO in 1997. Jobs placed great emphasis on simplicity and focus, quality and perfectionism as well as unconventional ideas and approaches. He applied these personal qualities to the entire way the company operates, creating the right environment for Apple's innovative product development [56]. Secondly, Apple showed a keen sense of the right timing of strategic decisions. For example, the iPod was not introduced until the necessary boundary conditions (P2), i.e. a whole $\mathrm{mp} 3$ player ecosystem, were in place [58].

These success factors enabled Apple to leverage different technological changes brought by digitalization as highly profitable opportunities for digital innovation. For this reason, Apple can be seen as one of the most resilient companies in the last 20 years and as an archetype for organizational resilience. In comparison, Sony was more reluctant to adapt to technological changes, such as MP3 files in our case study of the Sony Walkman. Other related cases, such as the decline of Sony Ericson Walkman phones and Sony's missed change towards LCD-powered televisions support this interpretation. However, at the same time, Sony also innovated revolutionary digital products such as the PlayStation, and earlier the Sony Walkman. For this reason, we cannot extrapolate from our results to the company Sony as a whole. Nevertheless, the case of Sony Walkman illustrates the effects of hesitant reactions to technological changes in the business environment. 


\subsection{Netflix's David vs. Goliath Story of Constant Innovation}

Table 5. Case vignette of Netflix's success story.

\section{Case Vignette: Netflix's David vs. Goliath Story of Constant Innovation}

Initial Situation: The mass production of video equipment in the early 1980s opened up a large market for video stores, such as the US rental chains Blockbuster Video or Movie Gallery, that rented VHS cassettes for a minor fee.

Technological Shift: DVDs as a lower-weighted storage technology, the rapid evolution of e-commerce in the early 2000s, and later, the wide-spread access to broadband infrastructure put high pressure on brick-and-mortar stores in the videoon-demand business [60].

Market Development: Founded in 1997 as an online DVD rental service, Netflix relied exclusively on DVDs from the very beginning and offered a novel business model by solely accepting orders online and sending the requested movies per mail. This innovation was only possible due to the lower weight of the DVD compared to the VHS technology and became even more radical with Netflix's introduction of a flat-rate subscription model in 1999 [59]. Thanks to its trailblazing business model, Netflix's market share in the growing online video-rental segment was approx. 85\% in the early-mid 2000s, even though established firms such as Blockbuster reluctantly developed a similar online mail order service [59].

With the expansion of faster broadband connections and the development of more efficient data transmission algorithms, Netflix saw the opportunity and necessity to transform its business model as a home theater service provider. In 2007, they began to make movies and TV series accessible through ad-free online streaming and expanded this service all around the globe in the early 2010s. By gaining a firstmover advantage for the second time, Netflix increased its number of subscribers from 22 million in 2011 to nearly 150 million in 2019 [65] and had an annual profit of $\$ 1.2$ billion in 2018 [66]. Due to shared subscriptions, the amount of actual users of Netflix's offerings even exceeds the number of subscribers and represented approximately $37 \%$ of all global Internet users in 2019 [65].

Another remarkable business decision of Netflix was to create and stream their own productions, beginning with House of Cards in 2011, which is considered a key success factor in a nowadays highly-competitive segment [59]. By leveraging datadriven insights in customer needs as a competitive advantage [64], Netflix not only sets new standards in the video-on-demand business but also initiates changes in the entire movie and television industry [61, 67].

The case of Netflix's success story, summarized in Table 5, shows how Netflix repeatedly managed to anticipate environmental changes through innovation over the past 20 years [59]. Similar to Apple, Netflix's success today is not built on a single successful product innovation but rather on several internal capabilities, which allow Netflix to continuously reinvent itself. Thanks to these resilient characteristics, the 
company has been able to set itself apart from other video-on-demand providers such as Blockbuster Video, but also established film studios like Disney.

Poupakis [64] describes the reluctance of film studios to enter the market of streaming with Christensen's [10] innovator's dilemma, since the film studios might fear cannibalizing their pay-tv and box office business and, thus, put their high-profit business models at risk. However, especially in the face of disruptive technological changes such as digitalization, this can become a rapidly growing threat to established companies due to new competitors [42]. Due to the importance of network effects and the collection of vast amounts of user data, digital disruptions such as streaming platforms are more likely to be accompanied by "winner-takes-it-all" markets than traditional businesses [43]. However, if a company has sufficient organizational resilience, it can successfully deal with this threat through adaptive or transformative processes. In Netflix's case, the transformation of the company from an online DVD rental service to a streaming provider, but also the adaptation by adding in-house productions, are illustrative examples. Both times, the company managed to anticipate the change and transformed the threat into an opportunity for even greater success (S5). Despite extensive changes in its business model, Netflix retained its original mission, i.e. affordably providing its customers with their favorite movies and series with a high level of convenience, complemented with a mature recommendation system [62].

A key reason for Netflix's success lies in its innovative corporate culture and informal human resources practices. Netflix's human resources approach closely overlaps with our proposed factors of organizational resilience: Netflix emphasizes acting in the interest of the company (P1), sharing knowledge (S1), delegating responsibility (S3, P4), openly addressing mistakes (P3), and mutual understanding of the context (P2) $[63,68]$. Ideas such as the Netflix Prize - an open innovation challenge to improve Netflix' recommendation system with a $\$ 1$ million reward - are another indicator for Netflix's innovative mindset to identify opportunities for improvement (S4) and ensuring the availability of resources for a rapid innovation (S2) [62].

\subsection{Cross-case patterns}

Comparing the cases of Apple and Netflix, we found that both companies repeatedly developed groundbreaking innovations that became an integral part of today's entertainment industry. In contrast, other major players (Sony, Blockbuster, eventually Disney) have shied away from these necessary adoptions of their business model for too long. As described in the previous subsection, this hesitation can be attributed to the innovator's dilemma $[10,64]$. Apple and Netflix, on the other hand, seem to have recognized the right time to gradually replace their market-leading and highly profitable products such as the iPod and DVD distribution with more advanced innovations such as the smartphone and online streaming.

Hamel and Välikangas [23] and Teixeira and Werther [51] describe this ability to continually reinvent oneself through innovation as a core characteristic of organizational resilience in today's highly volatile business environment. This ability reflects, in particular, the following factors of organizational resilience (cf. Table 2): Availability of resources (S2), Coordination of business units (S3), Continuous 
improvement process (S4), Ability to anticipate change (S5), and Understanding and influencing the context (P2).

In addition to the ability to respond to a changing context through innovation, both share a distinctive corporate culture that strengthens trust in employees and facilitates the necessary processes of change. Both companies, similarly, select only excellent applicants but then transfer great freedom to them $[56,63]$. The managers in both companies establish a corporate culture that reflects the following factors of organizational resilience (cf. Table 2): Sharing information and knowledge (S1), Shared vision (P1), Understanding and influencing the context (P2), Encouraging leadership (P3), and Positive culture that promotes resilience (P4).

As a major difference between the analyzed cases of Apple's iPod and Netflix, we identified the timing of market entry. While Apple released its products with a certain delay compared to other MP3 players and early smartphones, Netflix used the firstmover advantage for both online DVD distribution and its streaming service. However, both cases indicate a deep understanding of the context and conditions of the respective markets. Therefore, Apple and Netflix both were able to identify just the right temporal window of opportunity for digital innovation, which we identify as a critical success factor for their digital transformation.

\section{Discussion and Conclusion}

Meanwhile, digitalization is affecting almost all established industries and business models with disruptive forces. As a result, innovation cycles are becoming increasingly shorter, and companies hesitating to change eventually get overwhelmed by the rapid change of digital disruptions [42]. Prominent examples give evidence for the widespread upheavals brought about by digitalization: Kodak's decline in the photo business, Uber's success vis-à-vis the established cab industry, and the success stories of Airbnb, Spotify, and Zalando. Netflix's founder Reed Hastings emphasizes in an interview that a successful way of working in creative companies like Netflix or Apple is fundamentally different from conventional industrial companies. While the latter primarily aim to reduce variance and thus errors, creative companies are successful by increasing variance and thus innovation [63]. This conflict poses severe and unsolved challenges for traditional companies aiming to digitally transform their organizations.

In this paper, we contribute to an understanding of digital innovation management by linking the concepts of organizational resilience and digital innovation and transformation. With a cross-case study of Apple and Netflix, we examine the decisive role of organizational resilience for successful digital innovation and transformation and show that digital transformation through innovation is a necessity to strive in the digital age. Thereby, our study reveals the following implications: First, we find systemic and personal resilience factors of organizational resilience, which help companies to prepare for temporal "distensions" facilitated by digital technologies providing opportunities for digital innovation. Aligned with innovation management, which is constantly looking out for these opportunities, this empowers companies to rapidly transform their business with digital innovation when the right moment has 
come. Second, we bridge between organizational theory and traditional innovation management as part of a transition towards digital innovation management by introducing a conceptual framework, which depicts the moderating effect of organizational resilience in the face of adverse circumstances such as technological disruptions. Finally, practitioners might use our case study as guidance as we showcase two examples of how to leverage organizational resilience by digitally transforming one's business [9] and, thus, avoiding the innovator's dilemma [10].

Our research certainly comes with some limitations. First, throughout our cross-case study, we mainly focused on two cases in a similar industry and business environment. Therefore, our results can only indicate the potential of organizational resilience for IS theory building in the context of digital innovation management and digital transformation. Second, due to the nature of the examined concept, it was difficult to collect sufficient internal data, which is why we also considered external data and journalistic material. Finally, we based our findings only on relevant literature and the insights from our case study, whereas they still lack a rigorous evaluation in practice.

However, these limitations at the same time leave the potential for future research. First, subsequent research might use our results for an in-depth qualitative or quantitative empirical study on the current digital readiness in less digitized industries such as construction and agriculture, e.g. by using questionnaires as in the work of Heller et al. [49]. Second, our work could serve as a basis for future endeavors aiming to derive targeted measures for companies to build organizational resilience and, thus, create preventive conditions to successfully deal with digital disruptions [42]. Finally, future work might apply our conceptualization as part of a case study in other industries, such as the financial or energy sector, to review and expand our findings, and thus, contribute to understanding the impact of organizational resilience for IS research.

\section{References}

1. Legner, C., Eymann, T., Hess, T., Matt, C., Böhmann, T., Drews, P., Mädche, A., Urbach, N., Ahlemann, F.: Digitalization: Opportunity and Challenge for the Business and Information Systems Engineering Community. Bus. Inf. Syst. Eng. 59, 301-308 (2017). https://doi.org/10.1007/s12599-017-0484-2.

2. Rachinger, M., Rauter, R., Müller, C., Vorraber, W., Schirgi, E.: Digitalization and its Influence on Business Model Innovation. J. Manuf. Technol. Manag. 30, 1143-1160 (2019). https://doi.org/10.1108/JMTM-01-2018-0020.

3. Wiesböck, F., Hess, T.: Digital Innovations: Embedding in Organizations. Electron. Mark. 30, 75-86 (2020). https://doi.org/10.1007/s12525-019-00364-9.

4. Abolhassan, F.: Was treibt die Digitalisierung? Warum an der Cloud kein Weg vorbeiführt. (2016).

5. Nambisan, S., Lyytinen, K., Majchrzak, A., Song, M.: Digital Innovation Management: Reinventing Innovation Management Research in a Digital World. MIS Q. Manag. Inf. Syst. 41, 223-238 (2017). https://doi.org/10.25300/MISQ/2017/41:1.03.

6. Henfridsson, O., Mathiassen, L., Svahn, F., Henfridsson, O.: Managing Technological Change in the Digital Age: The Role of Architectural Frames. (2014). https://doi.org/10.1057/jit.2013.30. 
7. Yoo, Y., Henfridsson, O., Lyytinen, K.: Research Commentary-The New Organizing Logic of Digital Innovation: An Agenda for Information Systems Research. Inf. Syst. Res. 21, 724-735 (2010). https://doi.org/10.1287/isre.1100.0322.

8. Eisenhardt, K.M.: Building Theories from Case Study Research. Acad. Manag. Rev. 14, 532-550 (1989). https://doi.org/10.2307/258557.

9. Linnenluecke, M.K.: Resilience in Business and Management Research: A Review of Influential Publications and a Research Agenda. Int. J. Manag. Rev. 19, 4-30 (2017). https://doi.org/10.1111/ijmr.12076.

10. Christensen, C.: The Innovator's Dilemma: When New Technologies Cause Great Firms to Fail. (2013).

11. Holling, C.S.: Resilience and Stability of Ecological Systems. Annu. Rev. Ecol. Syst. 4, 123 (1973). https://doi.org/10.1146/annurev.es.04.110173.000245.

12. Werner, E.E.: Vulnerable but Invincible. A Longitudinal Study of Resilient Children and Youth. Acta Paediatr. Int. J. Paediatr. Suppl. 86, 103-105 (1982). https://doi.org/10.1111/j.1651-2227.1997.tb18356.x.

13. Staw, B., Sandelands, L., Quarterly, J.D.-A. science, 1981, U.: Threat Rigidity Effects in Organizational Behavior: A Multilevel Analysis. JSTOR. https://doi.org/10.2307/2392337.

14. Meyer, A.D.: Adapting to Environmental Jolts. Adm. Sci. Q. 515-537 (1982). https://doi.org/10.2307/2392528.

15. Weick, K., Sutcliffe, K., Obstfeld, D.: Organizing for High Reliability: Processes of Collective Mindfulness. Res. Organ. Behav. 21, 81-123 (1999).

16. Luthans, F.: The Need for and Meaning of Positive Organizational Behavior. J. Organ. Behav. 23, 695-706 (2002). https://doi.org/10.1002/job.165.

17. Luthans, F., Vogelgesang, G.R., Lester, P.B.: Developing the Psychological Capital of Resiliency. Hum. Resour. Dev. Rev. 5, 25-44 (2006). https://doi.org/10.1177/1534484305285335.

18. Shin, J., Taylor, S., Seo, M.-G.: Resources for Change: The Relationships of Organizational Inducements and Psychological Resilience to Employees' Attitudes and Behaviors Toward Organizational Change. Acad. Manag. J. 55, 727-748 (2012). https://doi.org/10.5465/amj.2010.0325.

19. Sheffi, Y., Rice, J.B.: A Supply Chain View of the Resilient Enterprise. MIT Sloan Manag. Rev. 47, (2005).

20. Sáenz, M.J., Revilla, E.: Creating More Resilient Supply Chains. MIT Sloan Manag. Rev. 55, 22-24 (2014).

21. Sutcliffe, K.M., Vogus, T.J.: Organizing for Resilience. Posit. Organ. Scholarsh. Found. a New Discip. 94-110 (2003).

22. Bella, J. Di: Unternehmerische Resilienz. (2014).

23. Hamel, G., Valikangas, L.: The Quest for Resilience. Harv. Bus. Rev. 81, 52-63 (2003).

24. Endres, H., Weber, K., Helm, R.: Resilienz-Management in Zeiten von Industrie 4.0. IM+io Das Mag. für Innov. Organ. und Manag. (2015).

25. Palzkill, A.: Managementperspektiven für die Zivilgesellschaft des 21. Jahrhunderts. Manag. für die Ziv. des 21. Jahrhunderts. 27-43 (2014). https://doi.org/10.1007/978-3-65802523-6.

26. Walker, B., Holling, C.S., Carpenter, S.R., Kinzig, A.: Resilience, Adaptability and Transformability in Social-Ecological systems. Ecol. Soc. 9, (2004). https://doi.org/10.5751/ES-00650-090205.

27. Ostrom, A.L., Parasuraman, A., Bowen, D.E., Patrício, L., Voss, C.A.: Service Research Priorities in a Rapidly Changing Context. J. Serv. Res. 18, 127-159 (2015). https://doi.org/10.1177/1094670515576315. 
28. Brennen, J.S., Kreiss, D.: Digitalization. Int. Encycl. Commun. theory Philos. 1-11 (2016). https://doi.org/10.4324/9780203736319-36.

29. Vial, G.: Understanding Digital Transformation: A Review and a Research Agenda. J. Strateg. Inf. Syst. 28, 118-144 (2019). https://doi.org/10.1016/j.jsis.2019.01.003.

30. Hinings, B., Gegenhuber, T., Greenwood, R.: Digital Innovation and Transformation: An Institutional Perspective. Inf. Organ. 28, 52-61 (2018). https://doi.org/10.1016/j.infoandorg.2018.02.004.

31. Kohli, R., Melville, N.P.: Digital Innovation: A Review and Synthesis. Inf. Syst. J. 29, 200223 (2019). https://doi.org/10.1111/isj.12193.

32. Hunke, F., Seebacher, S., Schuritz, R., Illi, A.: Towards a Process Model for Data-driven Business Model Innovation. 2017 IEEE 19th Conf. Bus. Informatics. 1, 150-157 (2017). https://doi.org/10.1109/CBI.2017.43.

33. Barnett, T.J., Sumits, A., Jain, S., Andra, U.: Cisco Visual Networking Index (VNI) Update Global Mobile Data Traffic Forecast. (2015).

34. Davenport, T.H., Harris, J.G.: Competing on Analytics: The New Science of Winning. Harvard Business Review Press, Boston (2017).

35. Porter, M.E., Heppelmann, J.E.: How Smart, Connected Products Are Transforming Competition. (2014).

36. Hunke, F., Seebacher, S., Schymanietz, M., Jonas, J., Genennig, S., Kühne, B., Schüritz, R., Satzger, G., Möslein, K., Böhmann, T.: Geschäftsmodelle 4.0. In: Digitale Dienstleistungsinnovationen. pp. 167-183. Springer Berlin Heidelberg (2019). https://doi.org/10.1007/978-3-662-59517-6_9.

37. Hartmann, P.M., Zaki, M., Feldmann, N., Neely, A.: Capturing Value from Big Data - A Taxonomy of Data-driven Business Models used by Start-up Firms. Int. J. Oper. Prod. Manag. 36, 1382-1406 (2016). https://doi.org/10.1108/IJOPM-02-2014-0098.

38. Schüritz, R., Seebacher, S., Satzger, G., Schwarz, L.: Datatization as the Next Frontier of Servitization: Understanding the Challenges for Transforming Organizations. ICIS 2017 Proc. 1098-1118 (2017).

39. Hunke, F., Seebacher, S., Schüritz, R., Satzger, G.: Pathways from Data to Value: Identifying Strategic Archetypes of Analytics-Based Services. Proc. 15th Int. Conf. Wirtschaftsinformatik. (2020). https://doi.org/10.30844/wi_2020_j7-hunke.

40. Kim, Y.S., Street, W.N.: An Intelligent System for Customer Targeting: A Data Mining Approach. Decis. Support Syst. 37, 215-228 (2004). https://doi.org/10.1016/S01679236(03)00008-3.

41. Habryn, F., Kunze von Bischhoffshausen, J., Satzger, G.: A Business Intelligence Solution for Assessing Customer Interaction, Cross-Selling, and Customization in a Customer Intimacy Context. ECIS 2012 Proc. (2012).

42. Skog, D.A., Wimelius, H., Sandberg, J.: Digital Disruption. Bus. Inf. Syst. Eng. 60, 431437 (2018). https://doi.org/10.1007/s12599-018-0550-4.

43. Gawer, A., Cusumano, M.A.: Industry Platforms and Ecosystem Innovation. J. Prod. Innov. Manag. 31, 417-433 (2014). https://doi.org/10.1111/jpim.12105.

44. Deutsche Telekom AG: Digitalisierungsindex Mittelstand 2019/ 2020: Der Digitale Status Quo im Deutschen Handel. 1-12 (2019).

45. Folke, C.: Resilience: The Emergence of a Perspective for Social-Ecological Systems Analyses. Glob. Environ. Chang. 16, 253-267 (2006). https://doi.org/10.1016/j.gloenvcha.2006.04.002.

46. Dahles, H., Susilowati, T.P.: Business Resilience in Times of Growth and Crisis. Ann. Tour. Res. 51, 34-50 (2015). https://doi.org/10.1016/j.annals.2015.01.002. 
47. Avery, G.C., Bergsteiner, H.: Sustainable Leadership Practices for Enhancing Business Resilience and Performance. Strateg. Leadersh. 39, 5-15 (2011). https://doi.org/10.1108/10878571111128766.

48. ISO: ISO 22316:2017 - Security and Resilience - Organizational Resilience - Principles and Attributes, https://www.iso.org/standard/50053.html, last accessed 2020/10/15.

49. Heller, J., Huemer, B., Preissegger, I., Drath, K., Zehetner, F., Amann, E.G.: Messung organisationaler Resilienz: Zentrale Elemente, Schutz- und Risikofaktoren. In: Resilienz für die VUCA-Welt. pp. 133-139. Springer Fachmedien Wiesbaden (2019). https://doi.org/10.1007/978-3-658-21044-1_9.

50. Glaser, B., Strauss, A.: Discovery of Grounded Theory: Strategies for Qualitative Research. , Routledge (2017).

51. Teixeira, E. de O., Werther, W.B.: Resilience: Continuous Renewal of Competitive Advantages. Bus. Horiz. 56, 333-342 (2013). https://doi.org/10.1016/j.bushor.2013.01.009.

52. Meniuc, C.: Adaptive Cycle of Resilience: Netflix Case Study. (V)ODC Course 2013/2014. (2013).

53. Webster, J., Watson, R.T.: Analyzing the Past to Prepare for the Future: Writing a Literature Review. MIS Q. 26, xiii-xxiii (2002). https://doi.org/10.2307/4132319.

54. Hosokawa, S., Ollrogge, B.: Der Walkman-Effekt. Merve, Berlin (1987).

55. Bull, M.: Investigating the Culture of Mobile Listening: From Walkman to iPod. In: Consuming Music Together. pp. 131-149. Springer, Dordrecht (2006).

56. Isaacson, W.: The Real Leadership Lessons of Steve Jobs. Harv. Bus. Rev. 93-102 (2012).

57. Pothitos, B.A.: The History of Portable Music. Mob. Ind. Rev. 1-9 (2011).

58. Adner, R.: From Walkman to iPod: What Music Tech Teaches us About Innovation. Atl. 16 (2012).

59. Voigt, K.-I., Buliga, O., Michl, K.: Entertainment on Demand: The Case of Netflix. Bus. Model Pioneers. 127-141 (2017). https://doi.org/10.1007/978-3-319-38845-8_11.

60. Sim, G.: Individual Disruptors and Economic Gamechangers: Netflix, New Media, and Neoliberalism. Netflix Eff. Technol. Entertain. 21st Century. 185-201 (2016).

61. Burroughs, B.: House of Netflix: Streaming Media and Digital Lore. Pop. Commun. 17, 117 (2019). https://doi.org/10.1080/15405702.2017.1343948.

62. Rayna, T., Striukova, L.: $360^{\circ}$ Business Model Innovation: Toward an Integrated View of Business Model Innovation. Res. Technol. Manag. 59, 21-28 (2016). https://doi.org/10.1080/08956308.2016.1161401.

63. McCord, P.: How Netflix Reinvented HR. Harv. Bus. Rev. 1-14 (2014).

64. Poupakis, S.: The Reason Hollywood Giants Waited so Long to Challenge Netflix. Quartz. Nov 12 (2019).

65. Watson, A.: Netflix - Statistics \& Facts. Statista. 1-6 (2020).

66. Watson, A.: Netflix: Net Income 2000-2018. Statista. 2018, 2019-2021 (2020).

67. Barnes, B.: The Streaming Era has Finally Arrived. Everything is About to Change. New York Times. 1-5 (2019).

68. Hastings, R.: Netflix Culture: Freedom \& Responsibility. Netflix Jobs. 16 (2009). 